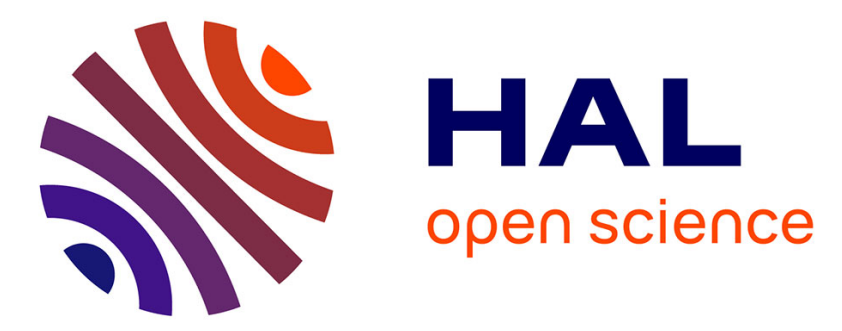

\title{
Deriving large-scale glacier velocities from a complete satellite archive: Application to the Pamir-Karakoram-Himalaya
}

\author{
Amaury Dehecq, Noel Gourmelen, Emmanuel Trouvé
}

\section{To cite this version:}

Amaury Dehecq, Noel Gourmelen, Emmanuel Trouvé. Deriving large-scale glacier velocities from a complete satellite archive: Application to the Pamir-Karakoram-Himalaya. Remote Sensing of Environment, 2015, 162, pp.55-66. 10.1016/j.rse.2015.01.031 . hal-01154166

\author{
HAL Id: hal-01154166 \\ https://hal.science/hal-01154166
}

Submitted on 6 Jan 2016

HAL is a multi-disciplinary open access archive for the deposit and dissemination of scientific research documents, whether they are published or not. The documents may come from teaching and research institutions in France or abroad, or from public or private research centers.
L'archive ouverte pluridisciplinaire HAL, est destinée au dépôt et à la diffusion de documents scientifiques de niveau recherche, publiés ou non, émanant des établissements d'enseignement et de recherche français ou étrangers, des laboratoires publics ou privés. 


\title{
Deriving large-scale glacier velocities from a complete satellite archive: Application to the Pamir-Karakoram-Himalaya
}

\author{
Amaury Dehecq ${ }^{\mathrm{a}, *}$, Noel Gourmelen ${ }^{\mathrm{b}}$, Emmanuel Trouvé $^{\mathrm{a}}$ \\ ${ }^{a}$ Université de Savoie - Polytech Annecy-Chambéry - LISTIC, BP 80439, 74944 \\ Annecy-le-Vieux cedex, France \\ ${ }^{b}$ University of Edinburgh, School of Geosciences, Edinburgh, EH8 9XP, UK
}

\begin{abstract}
Mountain glaciers are pertinent indicators of climate change and their dynamic, in particular surface velocity change, is an essential climate variable. In order to retrieve the climatic signature from surface velocity, large-scale study of temporal trends spanning multiple decades is required. Satellite image featuretracking has been successfully used to derive mountain glacier surface velocities, but most studies rely on manually selected pairs of images, which is not adequate for large datasets. In this paper, we propose a processing strategy to exploit complete satellite archives in a semi-automated way in order to derive robust and spatially complete glacier velocities and their uncertainties on a large spatial scale. In this approach, all available pairs within a defined time span are analyzed, preprocessed to improve image quality and features are tracked to produce a velocity stack; the final velocity is obtained by selecting measures from the stack with the statistically higher level of confidence. This approach allows to compute statistical uncertainty level associated with each measured image pixel.

This strategy is applied to 1536 pairs of Landat 5 and 7 images covering the 3000km long Pamir-Karakoram-Himalaya range for the period 1999-2001 to produce glacier annual velocity fields. We obtain a velocity estimate for $76000 \mathrm{~km}^{2}$
\end{abstract}

\footnotetext{
${ }^{*}$ Corresponding author

Email address: amaury.dehecq@univ-savoie.fr (Amaury Dehecq)
}

Preprint submitted to Remote Sensing of Environment

January 27, 2015 
or $92 \%$ of the glacierized areas of this region. We then discuss the impact of coregistration errors and variability of glacier flow on the final velocity. The median $95 \%$ confidence interval ranges from $2.0 \mathrm{~m} / \mathrm{yr}$ on average in stable areas and $4.4 \mathrm{~m} / \mathrm{yr}$ on average over glaciers with variability related to data density, surface conditions and strain rate. These performances highlight the benefits of processing of a complete satellite archive to produce glacier velocity fields and to analyse glacier dynamic at regional scales.

Keywords: Remote sensing, Feature-tracking, Surface velocity, Mountain glaciers, Landsat, Himalaya, Karakoram

1

\section{Introduction}

Mountain glaciers have a high societal impact; first on a local scale as they influence the water resources (Immerzeel et al., 2010) and economical activity (Barros et al., 2014) of a region, but also at a global scale by contributing to changes in the global sea level (Gardner et al., 2013). Moreover, mountain glaciers are sensitive to climate forcing and are thus relevant indicators of past and present climate changes (IPCC, 2013). Satellite imagery, with its global coverage and repeated acquistion, represents a unique opportunity to quantify the spatial and temporal changes affecting mountain glaciers. In particular, feature-tracking using repeated images allows us to construct velocity fields which are valuable information to understand dynamical processes such as the response to climate changes, glacier surges or development of glacial lakes and associated hazards (Paul et al., 2013).

Many studies have proven the capabilities of feature-tracking applied to repeated satellite images to measure glacier velocities. Scambos et al. (1992) applied normalized cross-correlation of Landsat TM images to measure the velocity of ice streams in Antarctica. Kääb (2002) and Berthier et al. (2005) show that it is possible to apply this method to mountain glaciers, using respectively ASTER and SPOT images. High resolution images as well as an improved algorithm, that determines the position of the correlation maximum from $1 / 2$ th to 
1/20th of a pixel (Strozzi et al., 2002), allow the tracking of much smaller surface features with a precision in yearly velocity of a few $\mathrm{cm} / \mathrm{yr}$, equivalent to the precision obtained by synthetic aperture radar interferometry (InSAR) (Goldstein et al. 1993) and multiple aperture InSAR (MAI) (Gourmelen et al., 2011). Particular attention has been given to improving the techniques of feature-tracking. Preprocessing steps to enhance and improve the performances of the tracking include Principal Component Analysis, high-pass filters (Scambos et al., 1992 , Berthier et al., 2005) or edge-detection (Ahn and Howat, 2011). Several studies focused on the choice of the feature-tracking algorithm (Strozzi et al., 2002, Heid and Kääb, 2012a), reduction of the orthorectification errors (Scherler et al. 2008 ) or on optimizing the parameters for the feature-tracking (Debella-Gilo and Kääb, 2012). However, automatation of the processing in order to reduce user interaction remains a challenge Ahn and Howat, 2011; Debella-Gilo and Kääb, 2012, Heid and Kääb, 2012a).

The large amount of currently available and future remote sensing data has led to a large variety of applications. Copland et al. (2009) produced velocity fields on a regional scale, for all glaciers within the central Karakoram region for the period 2006-2007, thereby giving an instantaneous picture of the glacier velocity in this region. This technique has also been applied to SAR images, to study specific areas such as the Mont-Blanc glaciers (Fallourd et al. 2011), the Everest region (Luckman et al., 2007) and the Baltoro glacier (Quincey et al. 2009a). Heid and Kääb (2012b) exploit the long time span of Landsat images to investigate the link between variations in mass balance and velocity over the period 1985-2011 for 6 selected regions across the globe. However, they also outline the problem of the representativeness of the selected regions and the need to increase the efforts at a regional scale. Several studies have processed larger number of images to produce velocity fields at a regional scale. Willis et al. (2012) processed 124 manually selected ASTER images to produce a velocity field for the $3593 \mathrm{~km}^{2}$ Northern Patagonian Icefield and the period 2000-2011. They obtain a composite velocity by averaging the stack of velocities weighted by the uncertainty of each velocity. Burgess et al. (2013) apply feature-tracking to 
344 pairs of ALOS images acquired between 2007 and 2010 but only 60 pairs are manually retained to produce a final mosaic velocity of the Alaska range glaciers. Scherler et al. (2011b) produce center flow line velocities for several parts of the himalayan range by computing the mean of a stack of velocities obtained from feature-tracking of 657 ASTER and SPOT images for the period 2000-2008. Nevertheless, all of these studies always rely on manually selected images and the repetitivity of the satellite imagery archive has not been exploited yet.

In this paper, we present a processing strategy to derive a robust and spatially dense velocity field over an extended region from a complete satellite archive. First, we give a broad outline of the method, we then apply this strategy to the Landsat 5 and 7 archive to produce glacier annual velocity fields over the Pamir-Karakoram-Hiamalaya (PKH) over a three-year period. This allows us to assess the performance and uncertainties of the strategy.

\section{Data and methods}

In this section, we describe the processing strategy including the selection of image pairs, the preprocessing steps to reduce the dimensionality of the problem and enhance the useful information, the feature-tracking algorithm and the fusion of the multi-temporal results (Figure 1). The method can be applied to any satellite imagery archive with sufficient repetition in the aquisition as for example ASTER, SPOT or the upcoming Sentinel 1 and 2 missions of the European Space Agency that will provide repeated images of the Earth surface. In this paper we focus on the Landsat serie that represents the longest continuous satellite archive, with acquisitions of the Earth surface from 1972 to nowadays and a repeat-cycle of 16 to 18 days at medium-resolution (15 to 60m) and a quasi-global coverage.

\subsection{Selection of image pairs}

The main idea of the method is to process all available data without manual selection for several reasons. First, selecting the images beforehand with 


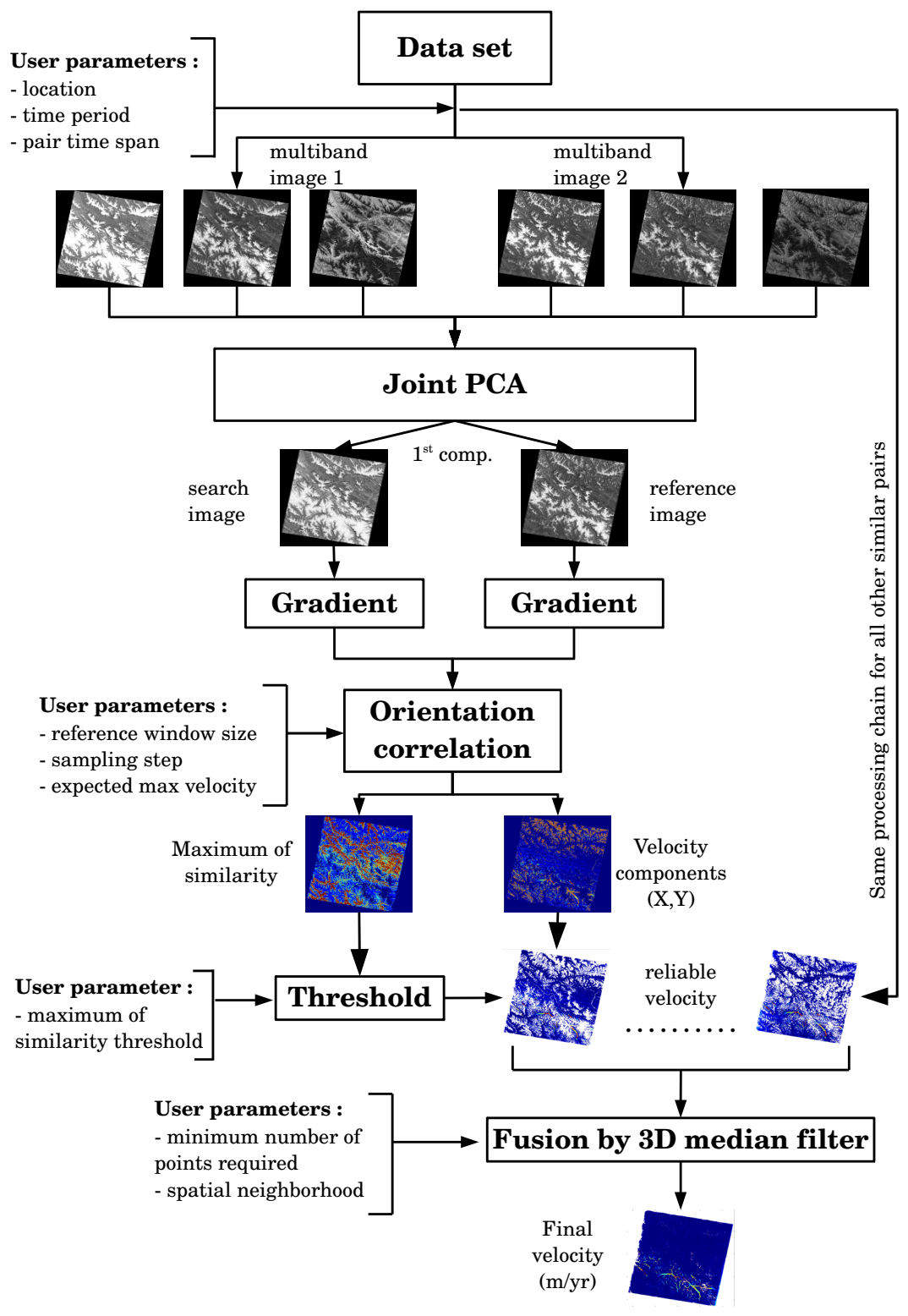

Figure 1: Processing strategy to derive glacier velocities from a complete multispectral satellite archive 
consideration of the quality of the scene is very time consuming and subjective and could lead to a loss of valuable information. Here we propose to process all data and to filter the results based on the quality of the feature-tracking. Secondly, a single pair rarely gives an spatially complete result due to shadows, clouds or sensor saturation that induce outliers or gaps in the resulting data. But several pairs might be complementary, allowing a more spatially complete estimate of the velocity field. Thirdly, we can exploit data redundancy to reduce the uncertainty in the results.

Thus images are selected solely based on the date and time of acquisition and location. Pairs are then formed with a specific time span. In order to produce, for example, annual velocity fields, we select pairs separated by one year, or multiples of a year, to minimize the effects of the seasonnal variability. It also increases the chances that the two images have a similar surface condition (linked to snow cover) which will improve the performance of the feature-tracking. Finally, the time span has to be large enough so that the displacement is significant with reference to the pixel size. Here, we obtain an annual velocity for year $\mathrm{T}$ by selecting all pairs of the form $(\mathrm{T}-1 ; \mathrm{T})$ and $(\mathrm{T}$; $\mathrm{T}+1)$, as well as $(\mathrm{T}-1 ; \mathrm{T}+1)$, so that all velocity measured are centered around year T. For example, the Landsat 5/7 repeat cycle is 16 days, and 23 cycles represent 368 days, so not exactly one year, so we process pairs that have temporal baselines of 368-16, 368 and 368+16 days for one year and 736-16, 736 and $736+16$ days for 2 years. Thus each image is paired with up to 6 other images. This allows us to compensate for some missing or poor quality images.

\subsection{Preprocessing}

\subsubsection{Image coregistration}

We assume that the images are corrected for topographic distorsion, i.e. that the displacement observed between two images is actual horizontal motion and not influenced by topography. But as some images are not exactly georeferenced, they are first coregistered to a reference image. We chose to use the Global Land Survey as a reference data set that have a positional 
accuracy better than $50 \mathrm{~m}$ (Tucker et al., 2004). Coregistration consists in : computing the offsets on a regular grid (typically 100x100 estimates), fitting a degree 2 polynomial and resampling to the reference image grid using Sinc interpolation. The resampling is done only if more than $10 \%$ of the pixels have offsets higher than 0.5 pixels in order to preserve the actual radiometry of images that are already well coregistered. Higher order offsets may still appear, mainly due to instrumental uncertainties that cannot be corrected due to the whiskbroom Landsat aquisition system (Scherler et al. 2008), but as long as they are not coherent between images, they will be efficiently filtered out by the proposed strategy. All images of the same frame are then cropped to a common region to ensure that the correlation windows are the same from pair to pair and the measurement always corresponds to the same region. We use the coordinates of the frame corners provided by the USGS in shapefile format (https://landsat.usgs.gov/tools_wrs-2_shapefile.php) to consistently crop the images.

\subsubsection{Principal Component Analysis}

Images are then enhanced in order to improve the quality of the featuretracking algorithm. Different steps have been proposed : Principal Component Analysis (PCA) to reduce the dimensionality of multi-spectral images, edge filters to enhance crevasse contours and high-pass filters for removing larger scale variations. (Scambos et al., 1992, Berthier et al., 2003, Ahn and Howat 2011).

The PCA is the procedure of projecting a set of different observations of the same variable, possibly correlated, into a new set of uncorrelated observations. It is constructed so that the first component maximizes the variance of the variable, then the second component maximizes the variance while being orthogonal to the first etc... It is interesting as it enhances the signal into a single value but the choice of the bands to be merged is a difficult task as it depends on the gain of the acquisition, the surface conditions of the glacier (e.g clean or debriscovered) and the sensor. Heid and Kääb (2012a) use the Landsat panchromatic 
band because of its higher resolution whereas Scambos et al. (1992) and Berthier et al. (2003) apply a Principal Component Analysis (PCA) on near-infrared and visible bands (1-5 for TM and ETM+) and use the first component, but this method does not explore the choice of the bands. Necsoiu et al. (2009) produce a combination of ASTER bands 1 and 2 to improve the performance of the correlation with SPOT panchromatic images. Redpath et al. (2013) determine the best band or band combination by comparing the result of the featuretracking of ASTER images with ground truths.

As we are seeking a method that can be exploited globally, we decide not to rely on ground truth for this step but rather on the performance of the feature-tracking itself. First, a few representative scenes of the studied region are selected. For each of these scenes, the feature-tracking is run for each band individually and the performance assessed using the success rate as defined in section 2.5. Once the best band or bands according to this criteria are determined, several band combinations can be considered. Every combination is then compared to the others using the same criteria and eventually an optimal band or band combination can be chosen. The results of this method for our study case is detailed in section 3

Finally, we noticed that the result of the PCA can vary much from image to image, mostly due to changes in snow cover. In order to avoid correlating different band combinations, we perform the PCA on a concatenation of the 2 images of the pair instead of performing it for each image individually. This choice ensures that the same physical signal (same combination of spectral bands) is introduced in the correlation step. The PCA has thus to be applied for each pair specifically.

\subsubsection{Intensity gradient}

Two Sobel kernels of size $3 \times 3$ are applied to compute the intensity gradient in the $\mathrm{x}$ and $\mathrm{y}$ directions, which enhances surface features such as crevasses and serac or debris cover. The gradients are normalized in order to produce an orientation image, which is the input for the feature-tracking algorithm described 


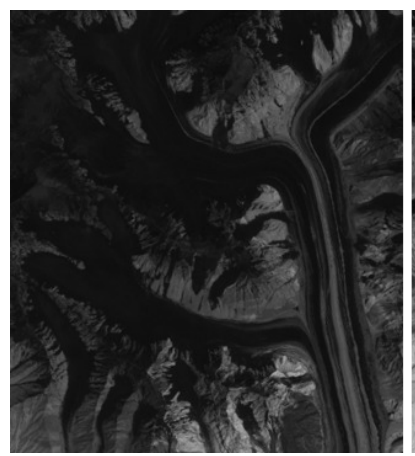

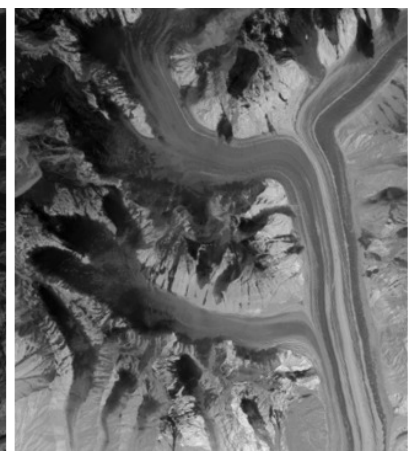

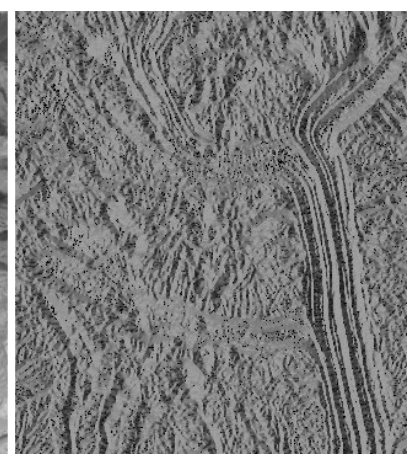

Figure 2: Example of enhancement procedure for Landsat images over northern tributaries of the Baltoro glacier (Karakoram) : Landsat mid-infrared band 5 (left) has the best performance in the Karakoram (see section 3.2.2, selecting the first component of a PCA of bands 4 \& 5 results in brightening of the accumulation zones (middle), the gradient orientation displays enhanced glacier features (right).

\subsection{Feature-tracking}

Feature-tracking is a method that allows the estimation of a displacement between a first image called reference image and a second image or search image. First, a window $\Omega_{r}$ is chosen in the reference image centered around pixel $(\mathrm{i}, \mathrm{j})$. Then a window of same size is extracted from the search image but translated by $(p, q)$ pixels within a specified search window $\Omega_{s}$ and compared to $\Omega_{r}$ using a function of similarity. This operation is repeated for different values of $(p, q)$ and the position of the maximum of similarity, interpolated to a fraction of pixel, is a measure of the displacement.

\subsubsection{Algorithm}

After a comparison between 6 different methods, Heid and Kääb (2012a) showed that the method called "orientation correlation" proposed in Fitch et al. (2002) has the best performance over mountain glaciers. Thus we focus only on this algorithm that is fast, illumination invariant and not sensitive to uniform areas such as in the saturated accumulation zones or the null-stripes that 
appear in the Landsat 7 ETM+ images after May 2003. In this algorithm, a synthetic complex image, called orientation image, is formed by setting the real and imaginary parts to the gradients in the $\mathrm{x}$ and $\mathrm{y}$ directions of the image intensity (I), respectively, and normalizing the quantity in order to take only the orientation into account (Fitch et al., 2002) :

$$
f= \begin{cases}\frac{g_{x}+i g_{y}}{\sqrt{g_{x}^{2}+g_{y}^{2}}} & \\ 0, & \text { if } g_{x}=g_{y}=0\end{cases}
$$

$$
\text { where } g_{x}=\frac{\partial I}{\partial x}, \quad g_{y}=\frac{\partial I}{\partial y},
$$

Because the input images are complex, we perform a complex cross-correlation between the two orientation images. The similarity function is given for each pixel $(p, q)$ by :

$$
C O(p, q)=\frac{1}{n}\left|\sum_{(i, j) \in \Omega_{r}} f_{r}(i, j) f_{s}^{*}(i+p, j+q)\right|
$$

where $n$ is the number of points in the reference window $\Omega_{r}, f_{r}\left(f_{s}\right)$ the orientation image of the reference (search) image and $f_{s}^{*}$ is the complex conjugate of $f_{s}$ (this formula is simplified by the fact that the images being correlated are already normalized). Concretely, we match the orientation of the intensity gradient that is contained in the phase of the orientation image (see Figure 2 right). We use the coherence tracking function proposed by Strozzi et al. (2002) that allows to track the gradient orientation which is contained in the phase of the orientation image. The coherence is computed in the Fourier domain and the maximum interpolated to a fraction of a pixel. The program also returns the Signal-to-Noise Ratio (SNR) i.e. the ratio between the correlation maximum and the average value in the search window which is a commonly used proxy for the confidence of the matching (Strozzi et al., 2002, Quincey et al. 2009a).

\subsubsection{Parameters setting}

The optimum parameters for the feature-tracking, i.e. the reference and search window sizes must then be chosen. The choice of the reference window 
size is complex since it must be large enough to avoid correlating only noise but small enough to avoid deformation of the matched objects inside the window. We perform the offset-tracking for a few selected pairs and different reference window sizes $\gamma_{r}$ and choose the lowest value that minimizes the errors in stable areas. It ensures that the window is large enough with respect to the image resolution while retaining the highest possible spatial resolution. This choice might not be optimal for all glaciers because it depends on the texture and size of the glaciers, but more sophisticated methods such as locally adaptive reference window sizes (Debella-Gilo and Kääb, 2012) are computationally too expensive for processing a large number of images.

The search window is chosen to be larger than the expected maximum displacement but small enough not to increase unnecessarily the computation time. For an expected maximum velocity $V_{\max }$ and a time span $\Delta t$ between two images of pixel size $R$, the search window size is set to $\gamma_{s}=2 V_{\max } \Delta t / R+\gamma_{r}$.

\subsection{Postprocessing}

After processing all the selected pairs, it is important to filter the displacement vectors and to merge all results into a single value. In the following sections, we propose a method to exploit the redundancy in the series of pairs in order to efficiently remove outliers and produce a more robust velocity field with very little user interaction.

\subsubsection{Outliers removal}

Mismatches or outliers are identified and removed using a threshold value of SNR. The choice of the threshold is a compromise between removing most of the mismatches while retaining the interesting information. The threshold can be easily determined by looking at the residuals in stable areas (see MAD in section 2.5. We show in section 3.2.3 that the residuals are high for low thresholds and drop dramatically to reach an asymptot in the range of the coregistration errors. Thus, we recommend to compute the MAD in stable areas for different SNR thresholds and select the lowest threshold that approaches the asymptot. 


\subsubsection{Fusion into a single velocity}

At this stage, we have a set of displacement fields that may contain gaps but also redundant values. The idea is to exploit the redundancy of information and physical properties of the glaciers to merge this set into a single, more robust velocity. We propose to compute a median of all neighbouring values both in a spatial and temporal neighbourhood, for each $\mathrm{x}$ and $\mathrm{y}$ component of the velocity. To ensure that the median is statistically significant and in order to remove spatially isolated pixels, we do not retain the value of the velocity if the number of points used to compute the median is less than a certain value Nmin. This method relies on two assumptions. First, because pairs were selected with similar time spans within a specified period, we assume that the measured velocity does not vary much from pair to pair. Secondly, we assume that the shear of the ice is low and that adjacent pixels on a glacier do not have large velocity differences. This is arguable at the edge of the glaciers where the moving ice is adjacent to the stable moraine and there might be a strong gradient. Nevertheless, a median filter preserves edges and thus glacier contours. The size of the spatial window for the median filtering depends on the image resolution and the number of pairs available (the more points we have, the smaller the window can be) and the size of the glaciers. For mountain glaciers, this spatial window should not exceed a few hundred meters.

This method offers several advantages. First, the median is not sensitive to isolated outliers and thus is able to filter out aberrant values that were not removed in the first stage. The use of a median filter to discard aberrant values is common in glaciology Copland et al. 2009, Ahn and Howat, 2011, Heid and Kääb, 2012a), but this method still requires supervision by an expert to select the threshold and is region-dependent (Heid and Kääb, 2012a). By adding more information with a set of displacement fields, we can minimize the expert interaction. Secondly, several factors (orthorectification errors, shadows, clouds) can induce matches with high confidence, because the features actually match between the two images, but are not related to actual terrain motion. This 
is often the main source of errors when applying feature-tracking to satellite images. But because these errors are not coherent from pair to pair, the median is not affected and the result of the fusion is still robust.

At last, in order to merge together velocity fields over a large region, with possible overlap and different projections (for example, different Landsat frames are projected on different UTM zones), we recommend to set a global grid and to merge the velocity fields by taking the median value of neighbor estimates, both spatially and in the stack of pairs, at each node of the grid.

\subsection{Performance assessment indices}

In this section, we define the indices that are used throughout the study to evaluate the velocity fields. As noted by Burgess et al. (2013), the presence of mismatches in the velocity fields tend to stretch the tails of the velocity distribution. It is thus important to use robust statistical estimators Rousseeuw and Hubert, 2011). It is the reason why we suggest to use the median and Median Absolute Deviation (MAD) instead of the mean and standard deviation.

In the following, velocity estimates are considered as valid after applying the SNR threshold. Glaciers are delimited using version 3.2 of the Randolph Glaciers Inventory outlines (Pfeffer et al. 2014) except for some parts of the Karakoram where we used manually edited outlines due to a misalignment between the outlines and the actual glaciers location. The performance assessement indices we retained are :

- The success rate $S R$, which is the percentage of valid velocity estimates on glaciers.

- The normalized Median Absolute Deviation (MAD) of the velocity :

$$
M A D=1.483 \times \operatorname{med}(|V-\operatorname{med}(V)|)
$$

which is a robust equivalent of the standard deviation. When not mentionned, it is computed for the velocity magnitude $\mathrm{V}$, or for each component of the velocity when a different behavior is expected for the two 
components. In particular, in stable areas, i.e off glaciers, where the velocity $\mathrm{V}$ is supposed to be null, the MAD is :

$$
M A D_{o f f}=1.483 \times \operatorname{med}_{(i, j) \in \Omega_{o f f}}(|V(i, j)|)
$$

where $\Omega_{\text {off }}$ is the ensemble of points off glaciers. This is a proxy for the uncertainty of the measurement.

- The dispersion : during the fusion step, the MAD can be calculated at each velocity location.

$$
\sigma(i, j)=1.483 \times \operatorname{med}_{t \in T}(|V(i, j, t)-\bar{V}(i, j)|)
$$

where $T$ is the set of $N$ velocity estimates $V(i, j, t)$ merged to obtain the median velocity $\bar{V}(i, j)$ at pixel $(i, j)$. This is indicative of the variability between the different velocity estimates.

- The coherence of the velocity vectors that contributed to the median, i.e. if they point in the same direction. We define the Velocity Vector Coherence (VVC) as :

$$
V V C(i, j)=\frac{\left\|\sum_{t \in T} \vec{V}(i, j, t)\right\|}{\sum_{t \in T}\|\vec{V}(i, j, t)\|}
$$

According to the triangle inequality, $\mathrm{VCC}$ is in the interval [0,1], equal to 1 if all vectors are perfectly aligned and tend to 0 if they point in random directions.

\subsection{Uncertainty}

Uncertainties of the single-pair velocity fields are dominated by the precision of the feature-tracking algorithm, the image to image registration and the temporal variability of glaciers flow. But the uncertainty of the final, i.e the median velocity over the considered period, is known to decrease with the number of estimates. Suppose a sample of size N drawn from a normally distributed 
population with variance $\sigma_{n}$, the sample median converges asymptotically to a normal distribution with standard deviation $\left.\sigma_{m}=\sqrt{\frac{\pi}{2}} \frac{\sigma_{n}}{\sqrt{N}} \sqrt{\mathrm{Chu}}, 1955\right)$. Here, we cannot make the hypothesis of a normal distributed velocity because of the possible presence of outliers, but because the different measurements are independant and symmetrically distributed, we assume that the $95 \%$ confidence interval of each component of the final velocity follows a similar law :

$$
t_{95}=k \frac{\sigma}{N^{\alpha}}
$$

where $\sigma$ is the MAD of the $N$ velocities used to compue the median velocity, $t_{95}$ the $95 \%$ confidence interval, i.e the difference between the 97.5 th quantile and the 2.5th quantile of the final velocity distribution, and $k$ and $\alpha$ parameters to be determined. Applying a logarithm to this equation, we obtain a linear relationship :

$$
\log \left(\frac{t_{95}}{\sigma}\right)=p_{0}+p_{1} \log (N)
$$

We propose to compute the $95 \%$ confidence interval in the stable areas, where the true velocity is know to be null, for each value of $N$. The relationship between $t_{95}, \sigma$ and $N$ is then fitted to equation 9 using a Least-square regression. This relationship is extrapolated to glacier areas to compute the $95 \%$ confidence interval of each component of the final velocity.

\section{Results}

\subsection{Data set}

We assess the ability of the processing strategy to produce glacier annual velocity fields over a large region. We thus process all Landsat pairs available between 1999 and 2001 over the Pamir-Karakoram-Himalaya (PKH) extending over $3000 \mathrm{~km}$. As mentionned earlier, we process all pairs of images with a time span in the list $368-16,368,368+16,736-16,736$ and $736+16$ days. It represents 1382 images, 1536 pairs, covering 68 Landsat frames. The location of the studied region and the processed frames is shown in Figure 5 . We use 
Table 1: Selected test pairs for the choice of the preprocessing and feature-tracking parameters

\begin{tabular}{|l|c|c|c|c|c|c|}
\hline Area & Path/Row & Sensor & First date & Second date & image 1 & Image 2 \\
\hline Karakoram & $148 / 35$ & LE7 & $25 / 02 / 2000$ & $27 / 02 / 2001$ & LE71480352000056SGS01 & LE71480352001058SGS00 \\
Everest & $140 / 41$ & LE7 & $30 / 10 / 2000$ & $17 / 10 / 2001$ & LE71400412000304SGS00 & LE71400412001290SGS00 \\
Kunlun Shan & $145 / 35$ & LT5 & $10 / 08 / 2007$ & $15 / 08 / 2009$ & LT51450352007222IKR00 & LT51450352009227KHC00 \\
\hline
\end{tabular}

the Level $1 \mathrm{~T}$ images, which are already terrain corrected using ground control points (GCPs) and Digital Elevation Models (DEMs) and available at no cost on the USGS website in GeoTIFF format in UTM projection. We downloaded the images using the Bulk Download Application available on the USGS website (https://lta.cr.usgs.gov/BulkDownloadApplication) that allows downloading a large set of images at once. Each image is roughly 8000x7000 pixels (or 16000x14000 for the panchromatic) and each scene is over 600MB in size. The processing of a pair takes approximately 15 minutes on an 8 cores desktop computer and the entire processing took 16 days.

\subsection{Parameters setting}

Because it would be time-consuming to define specific parameters for each of the available pairs, a few representative test pairs with a low cloud cover and good contrast have been selected to set the parameters that will be applied to all scenes. We selected three test pairs that are representative of different glaciers types in the PKH (Table 1). A first frame covering a large part of the Karakoram, north-west of the Himalaya is selected because it hosts some of the largest mountain glaciers. The second frame covers the Everest region that features smaller glaciers with an important debris cover which is an interesting property for feature tracking. The last frame over the Kunlun Shan features mostly clean-ice glaciers. Two different sensors, LE7 and LT5 have also been selected to account for possible differences.

\subsubsection{Feature-tracking parameters}

The most critical parameter for the feature-tracking is the size of the reference window $\gamma_{r}$. Figure 3 shows the MAD in stable areas as a function of 
the reference window size for the three test pairs and a SNR threshold of 5 . It clearly shows that for values of $\gamma_{r}$ below 12, the measured offsets are noisy, which is likely due to the small window size. Choosing higher values of $\gamma_{r}$ would reduce the noise even more, but it would also decrease the resolution of the results and increase the risk of deformation within the reference window, which is not desirable.

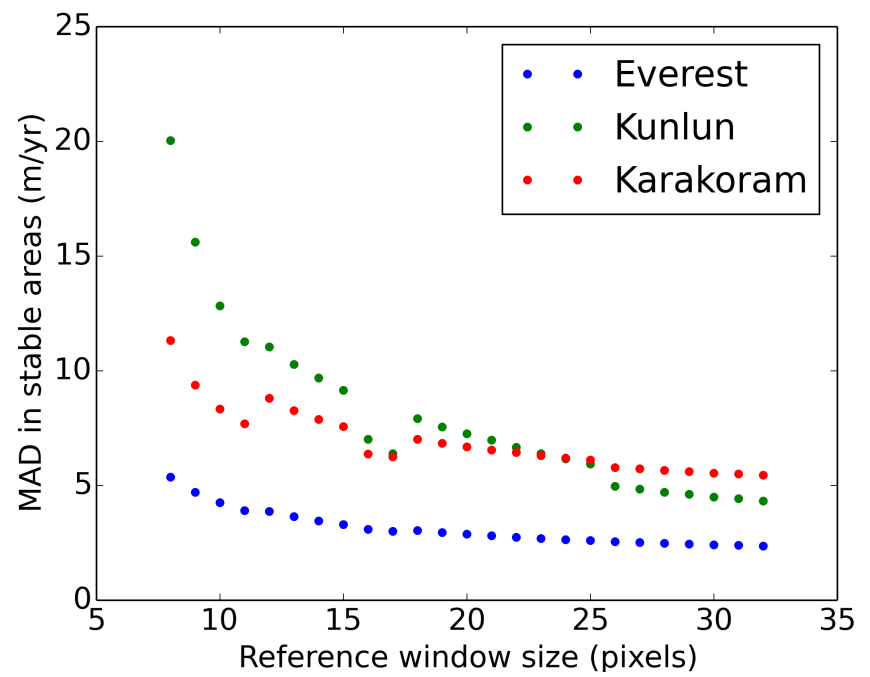

Figure 3: MAD of the velocity in stable areas as a function of the reference window size $\gamma_{r}$ for the three test pairs and a SNR threshold of 5

We thus set the reference window to $16 \times 16$ pixels $(480 \mathrm{mx} 480 \mathrm{~m})$ that approches a minimum in MAD while not being excessively large. Although not necessary, using a power of 2 optimizes the computation of the feature-tracking algorithm in Fourier domain. The search window is set to allow tracking displacements that are below $300 \mathrm{~m} /$ year, which is the case for most of the studied glaciers with the exception of the surging glaciers (Quincey et al. 2011). So it varies from 30 to 48 pixels depending on the pair time span. Images time span and search window are tuned to maximize precision and long-term trend, for study aimed at the study of glaciers with rapidly changing dynamics (e.g. 
surging glaciers,) these parameters can be adapted; e.g. the inclusion of pairs with shorter time span or larger search windows. We set the spacing between 2 correlation patches to half the reference window, so 8 pixels.

\subsubsection{Band selection}

We select the best band or band combination following the method described in Section 2.2 for the three test pairs. The success rate for each pair and band 1 to 5 (and panchromatic when available) are shown in Table 2 upper part, for a SNR threshold of 5. We observe that the visible bands 1 to 3 have low performance, this is due to saturation on snow and clean-ice. Then, band 5 gives the best results for the Everest and Karakoram region whereas band 4 is more interesting for the Kunlun region. The panchromatic band has better performances than the bands 1 to 3 but is still very saturated and doesn't give the best results on snow and ice. This ranking is not affected by the choice of the SNR threshold. This difference comes from differences in glaciers types. The Kunlun scene contains essentially clean-ice glaciers, which have a very low and almost uniform signal in band 5 (mid-infrared) and explain the poor performance for this band. On the contrary, the Everest and Karakoram regions contain many debris-covered glaciers which have a more homogenous response between all bands, but band 5 has a higher contrast in accumulation zones. In summary, band 5 has overall best performance in the accumulation areas where all others are saturated, except in shadows and over clean-ice where band 5 captures a very low signal (Figure 2). In those areas, band 4 has a higher contrast, thus band 4 and 5 seem to be complementary.

We then perform the same tests for the first component of different PCA combinations : the 1-5 combination that is used by Scambos et al. (1992) or Berthier et al. (2003), a combination that excludes band 5 and a combination of only bands 4-5. Results are shown in table 2 lower part.

They show that the combination of bands $4-5$ has the best performance in 
Table 2: Success rate of the feature-tracking over glaciers for each individual Landsat band (upper part) or different PCA combinations and component (lower part). The best value for each column is highlighted in bold. For the $15 \mathrm{~m}$ band 8 , the reference window has been set to $16 \times 16$ and $32 \times 32$ pixels to keep an identical window size in pixels and meters respectiveley.

\begin{tabular}{|l|c|c|c|}
\hline & Everest & Karakoram & Kunlun \\
\hline Band 1 & 8 & 7 & 4 \\
Band 2 & 10 & 13 & 10 \\
Band 3 & 9 & 8 & 8 \\
Band 4 & 24 & 9 & 15 \\
Band 5 & 42 & 40 & 9 \\
Band 8 (r16) & 19 & 14 & \\
Band 8 (r32) & 25 & 17 & \\
\hline $1,2,3,4,5$ & 37 & 48 & 15 \\
\hline $1,2,3,4$ & 24 & 14 & 15 \\
\hline 4,5 & $\mathbf{4 4}$ & $\mathbf{4 8}$ & $\mathbf{1 5}$ \\
\hline
\end{tabular}

all regions and it consistently performs better than any of the single bands. It seems to profit from the complementarity of bands 4 and 5 . This is not the case for the $\operatorname{PCA}(1,2,3,4,5)$ that has sometimes worse performances than the best band, as for example the Everest pair. So this band combination is not the best choice for studying mountain glaciers of different cover types. The results for PCA $(1,2,3,4)$ confirm that band 5 brings valuable information and shouldn't be excluded. In fact, it is the only band that differs significantly from all others on snow and ice and allows to increase the variance of the PCA. Again, these are robust conclusions for different choices of the SNR threshold (we tested 3, 5 and 7$)$.

In conclusion, the first component of $\mathrm{PCA}(4,5)$ is the band combination that has the most robust performance over mountain glaciers. 


\subsubsection{SNR threshold}

Once the feature-tracking parameters and the preprocessing steps are chosen, we can run the feature-tracking for each available pair to compute velocity fields and an associated SNR. These intermediate results allow us to set the SNR threshold used to remove residuals. Figure 4 shows the MAD in stable areas for each component of the velocity and the success rate for different SNR thresholds for all processed pairs. Low values of SNR mean that the reference and matching window don't match and the associated offsets are very noisy. But it is interesting to note that the MAD drops suddenly for SNR threshold higher than 3 and reaches an asymptot. The value of the asymptot represents the mean residuals for single pairs velocities, here it is in the range of $1-2 \mathrm{~m} /$ year and is slightly different for the $\mathrm{x}$ and $\mathrm{y}$ component. They are due to remaining orthorectification errors but thanks to the coregistration step they are reduced compared to estimated uncertainty in Landsat image to image registration (Lee et al. 2004, Storey and Choate, 2004). The success rate drops in the same way but continues to decrease for higher SNR threshold. Thus, we choose an SNR threshold of 4 that allows to substantially filter outliers while not removing too many interesting points.

\subsubsection{Fusion}

The individual velocity fields are then merged together using a median filter. The median velocity of each component is computed within all velocity fields and a spatial neighborhood. Because the Landsat frames over this large region are projected on different UTM zones, the median velocity is computed on a 240m Lambert conformal conic grid. Each velocity estimate within a radius of $\sqrt{2} \times 240=340 \mathrm{~m}$ is then included in the median, which means up to the nine closest neighbors are retained. Finally, if the number of data points used to compute the median is lower than $N \min =5$, we discard the measurement because the median is not robust enough. 


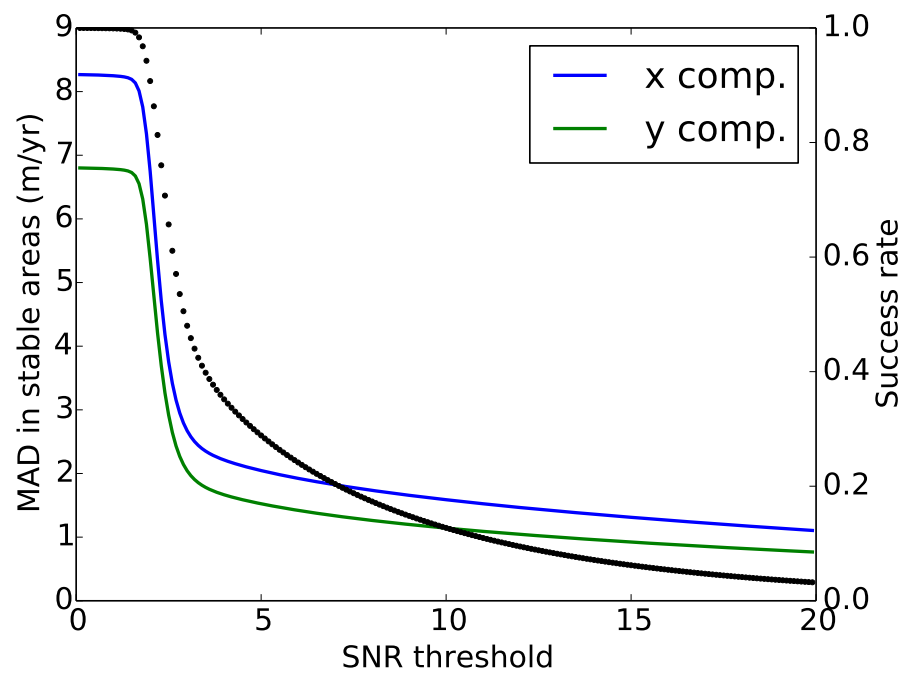

Figure 4: MAD of each component of the velocity in stable areas (plain lines) and success rate (black dots) for different SNR thresholds

\subsection{Final velocity fields}

The final velocity estimated for the PKH and year 2000 (period 1999-2001) is presented in Figure 5 for several subregions. A velocity has been estimated for $76000 \mathrm{~km}^{2}$ or $92 \%$ of the total glacierized areas within this region. Main gaps (red patches) correspond to the accumulation zones with low texture and specific glaciers flowing faster than $300 \mathrm{~m} /$ year, especially in the Karakoram. The pattern of the velocity fields are in good agreement with previous works, in particular Copland et al. (2009), Heid and Kääb (2012a) and Rankl et al. (2014) in the Karakoram (insert b), Quincey et al. (2009b) and Scherler et al. (2011b) in the Everest region (insert d), Kääb (2005) in Bhutan (insert e).

\section{Discussion}

\subsection{Contribution of the fusion versus single pairs}

In this section, we assess the performance of the processing of the complete archive compared to the results of single pairs for the frame 148/35 (East 


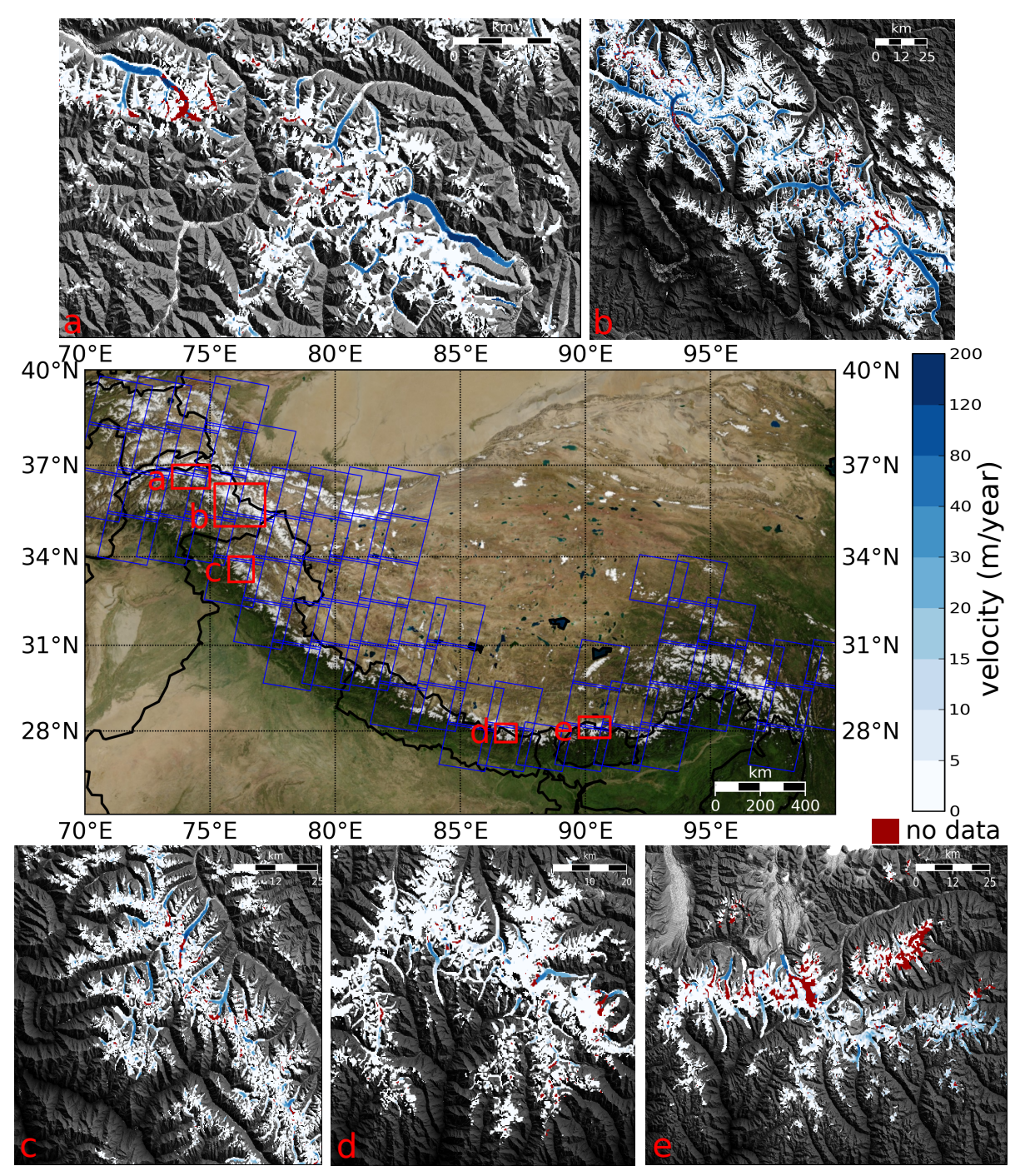

Figure 5: Map of the studied region : blue polygons show processed landsat frames, red squares highlight the position of the inserts a to e (a: Hindu-Kush, b : Karakoram, c : Jammu-Kashmir, d : Everest, e : Bhutan). Inserts show annual glacier velocity fields for year 2000 within the RGI masks (blue corlorscale). Red points are region without velocity estimate.

466 Karakoram) and year 2000 (pairs within the period 1999-2001). The data set ${ }_{467}$ is 26 images and 29 pairs. Figure 6 represents the effect of each step of the 
postprocessing for a velocity profile along the Baltoro glacier. The raw velocity fields (in grey) contain many aberrant values due to clouds and shadows in the images that need to be filtered out. Applying an SNR threshold of 4 removes most of them, but some outliers still remain and it does not ensure that the displacements are physically acceptable. By including more information, the spatio-temporal filtering method has several advantages : it efficiently removes outliers, it fills most gaps that may appear and gives a robust single value for each location.

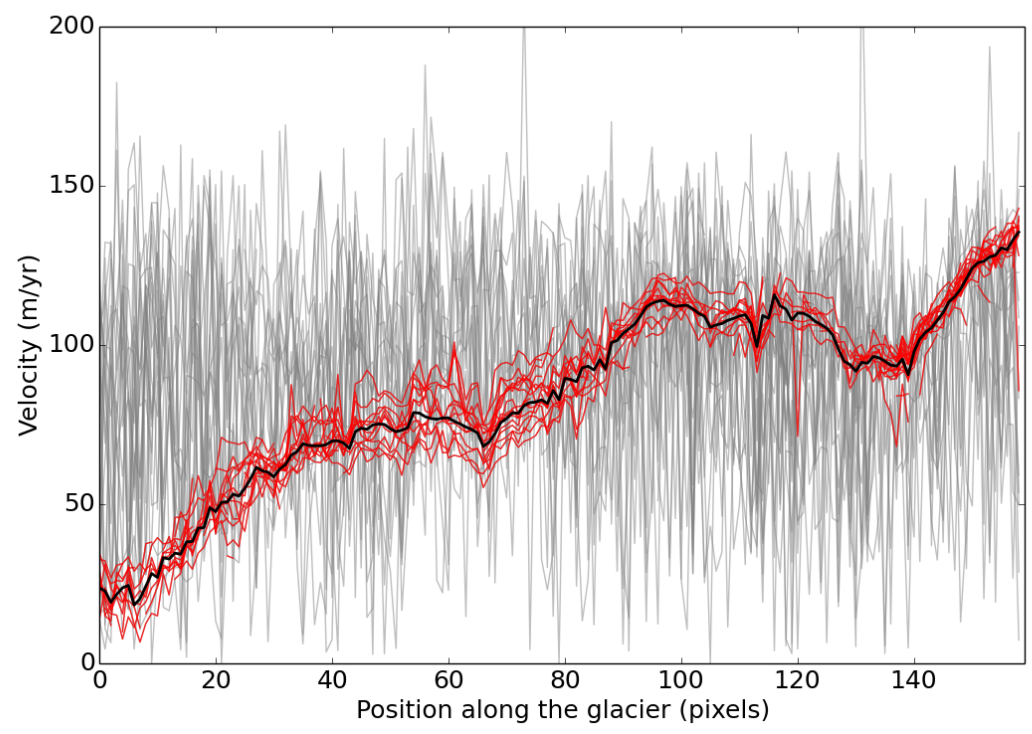

Figure 6: Velocity profiles along the Baltoro glacier (3542'29" N, 7623'21'E) for the 29 available pairs for years 1999 to 2001: unfiltered (grey), after selecting values with an SNR higher than 4 (red) and applying the spatio-temporal median (black).

More quantitatively, figure 7 (left) shows the success rate for each single pair and the fusion. The best single pair or optimum pair (i.e the pair with the highest success rate) allows an estimate of the velocity of $71 \%$ of the glacierized regions, main gaps are due to saturation in accumulation areas. Meanwhile, the result of the fusion returns a velocity estimate for $94 \%$ of the points. The fu- 


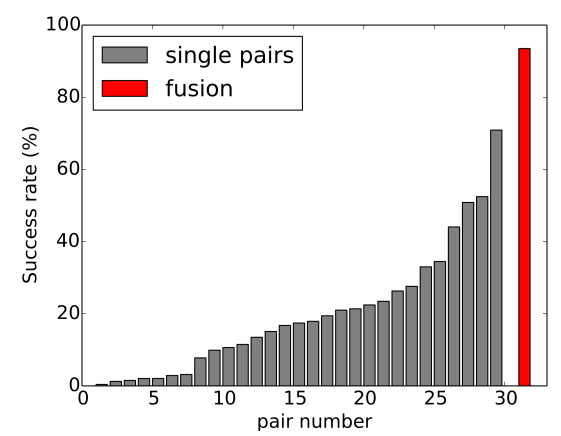
different pairs.

sion outperforms all individual pairs by exploiting the complementarity between

Figure 7 (right) shows the MAD in stable areas for each pair individually and for the result of the fusion. The MAD for the optimum pair is $5.5 \mathrm{~m} / \mathrm{yr}$ and the mean MAD for all single pairs $5.4 \mathrm{~m} / \mathrm{yr}$, mainly due to orthorectification errors. The fusion has the advantage of reducing this noise that is not correlated between successive pairs. As a consequence, the MAD for the fusion is $1.4 \mathrm{~m} / \mathrm{yr}$, gaining a factor of almost 4 on the optimum pair.

Figure 7: Left : Success rate for each individual pair, in ascending order and for the result of the fusion (red). Right : MAD in stable areas for same pairs in same order.

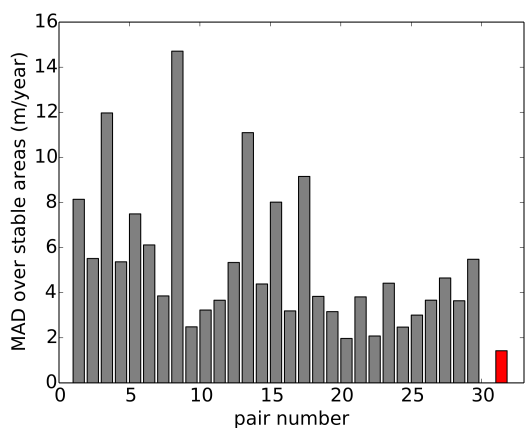

\subsection{Uncertainties}

In this section we show how the fusion approach allows to reduce the uncertainty of the final velocity fields with the example of the Karakoram subregion (74-78E, 34.5-37N). Figure 8 shows the dispersion of the single velocities around the median ( $\mathrm{cf} \mathrm{Eq} \mathrm{6).} \mathrm{It} \mathrm{highlights} \mathrm{the} \mathrm{two} \mathrm{main} \mathrm{sources} \mathrm{of} \mathrm{uncertainties.} \mathrm{The}$ first source of uncertainty is coregistration errors that are visible in the shape of large rectangles displaying the contours of the Landsat frames or correlated with the topography. Despite the coregistration with the GLS images, the mean dispersion over stable areas is $4.1 \mathrm{~m} / \mathrm{yr}$. The second source of uncertainty is the variability in glacier flow over the three year period. Glaciers are clearly visible on the figure in the shape of yellow or red tongues. In particular, a large 


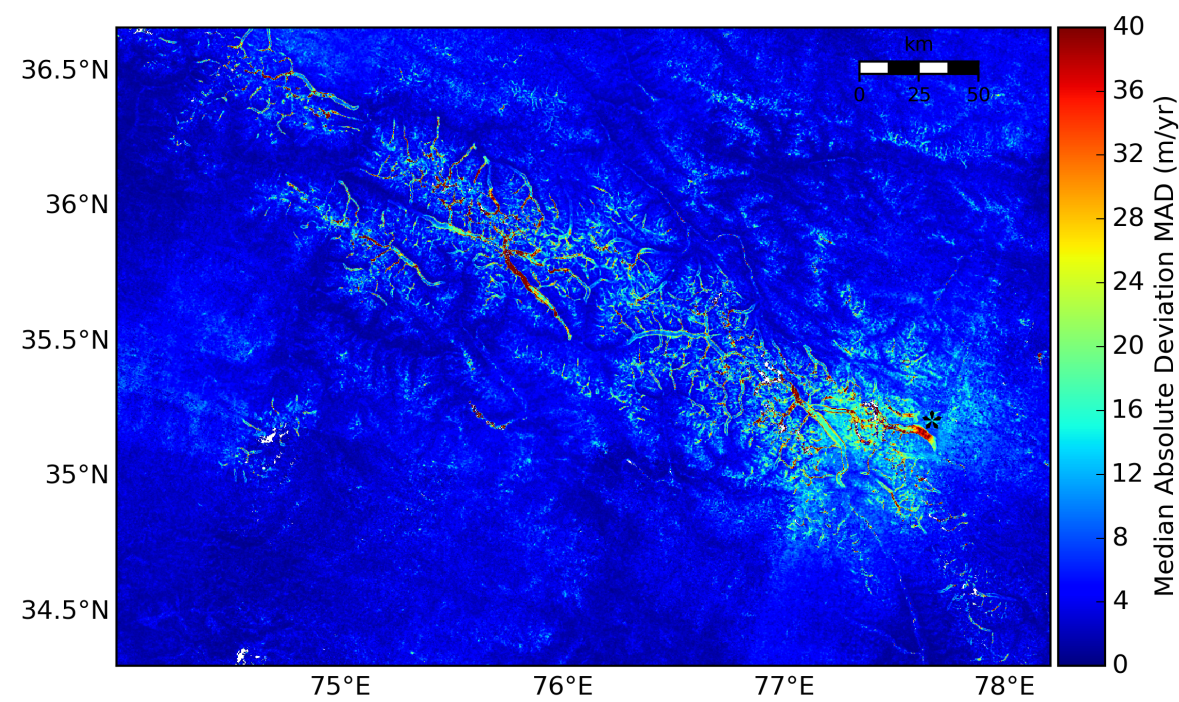

Figure 8: Dispersion of the velocities estimated from all pairs for the Karakoram and period

1999-2001

variability is observed on the central Rimo glacier (annoted with a ${ }^{*}$ ) of approximately $40 \mathrm{~m} / \mathrm{yr}$. This is coherent with the reported surging behavior of this glacier during that period (Bhambri et al. 2013). The mean dispersion over glaciers is $6.4 \mathrm{~m} / \mathrm{yr}$.

The uncertainty of the final velocity, i.e the median velocity, is impacted by the dispersion of the velocities but is reduced with an increasing number of observations. Figure 9 (left) shows the $95 \%$ confidence interval $t_{95}$ of the final velocity in stable areas as a function of the number of points used to compute the median. When few velocity estimates are available, i.e the measurement is spatially isolated or very few pairs allows for a measurement, the residuals reach over $20 \mathrm{~m} / \mathrm{yr}$ but as the number of merged velocity estimates increases, the confidence in the measurements reaches a few m/yr. Figure 9 (right) shows the linear relationship between $\log \left(t_{95} / \sigma\right)$ and $\log (N)$. The relationship is strong except for $N$ below $5(\log (N) \leq 0.7)$. Actually, for a low number of samples, the median and MAD are more difficult to estimate and their distributions diverge 
Table 3: Parameters for the linear regression between $\log \left(t_{95} / \sigma\right)$ and $\log (N)$

\begin{tabular}{|c|c|c|c|}
\hline Component & $\alpha$ & $\mathrm{k}$ & $R^{2}$ \\
\hline $\mathrm{x}$ & 0.44 & 4.0 & 0.94 \\
\hline $\mathrm{y}$ & 0.46 & 4.1 & 0.94 \\
\hline
\end{tabular}

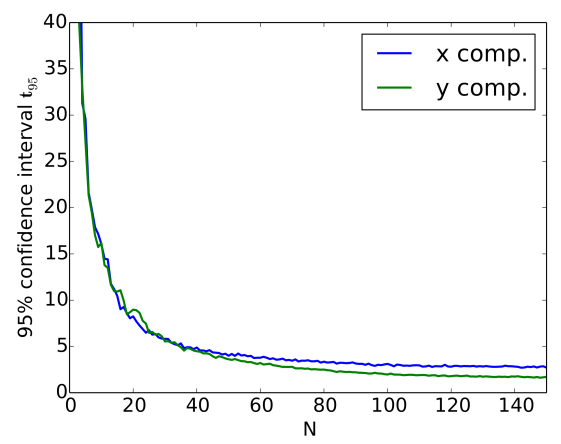

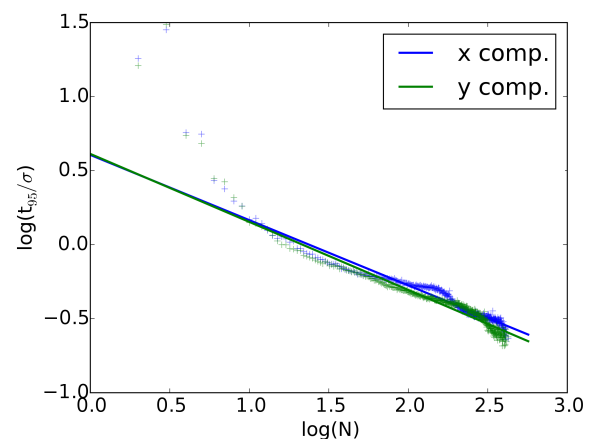

Figure 9: Residuals in stable areas as a function of the number of available velocity estimates for the Karakoram subregion

from the normal distribution. For these values, our method underestimate the uncertainty and we recommend to remove these points. For $N \geq 5$, the parameters of the regression are summarized in Table 3

This allows us to compute a $95 \%$ confidence intervall as a function of $\sigma$ and $N$. Figure 10 shows the result for the Karakoram region. The uncertainty map has a similar shape as $\sigma$ (Figure 8), but is weighted by $N$; in particular, on stable grounds where there are generally more measurements (less problems of saturation), the uncertainty is reduced whereas in snow covered areas, the low contrast reduces the number of measurements and uncertainty remains relatively high. The median uncertainty is $2.0 \mathrm{~m} / \mathrm{yr}$ in stable areas. Over glaciers, the median uncertainty is $4.4 \mathrm{~m} / \mathrm{yr}$, from a few $\mathrm{m} / \mathrm{yr}$ on some glaciers tongues to $10 \mathrm{~m} / \mathrm{yr}$ in some accumulation zones. The uncertainty is also higher on glaciers edges (as visible in the inset of Figure 10, due to higher strain rates and thus 
a more variable velocity within the reference window. Some grid patterns are also visible : they are due to the fact that the UTM and Lambert conic grids are not superposed and the number of neighbors varies periodically.
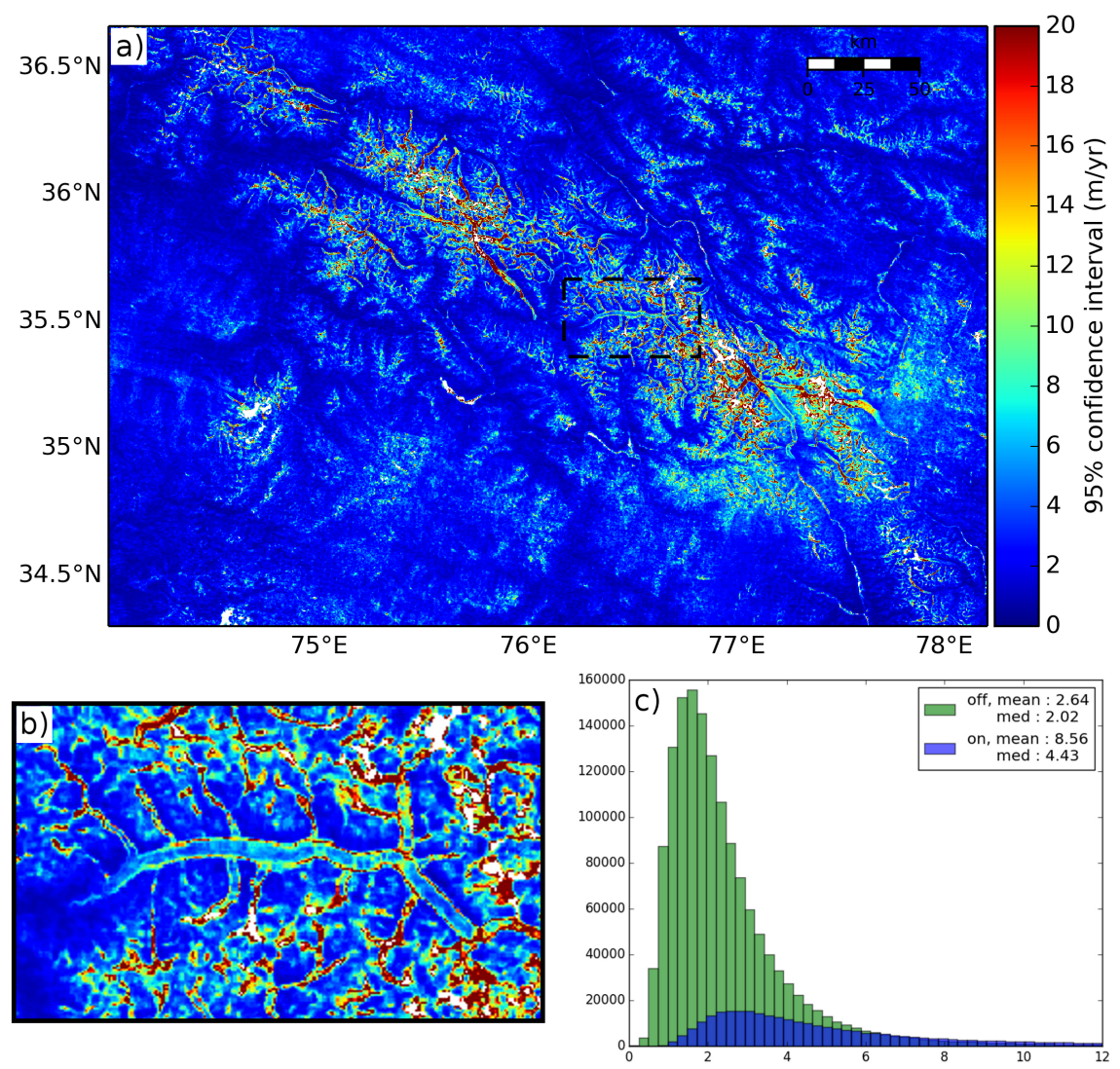

Figure 10: (a) Uncertainty of the final velocity for the Karakoram and period 1999-2001, (b) zoom over the Baltoro glacier (dash line), (c) histogram of the uncertainty on and off glacier

At last, the velocity vector coherence is illustrated in Figure 11 for the Karakoram region. Frame patterns or features correlated with topography remain in stable areas and are indicative of coregistration errors. Nevertheless, the coherence is much higher on glaciers which mean that the merged velocity vectors are well aligned and that we can be confident in the direction of the 
velocity field.

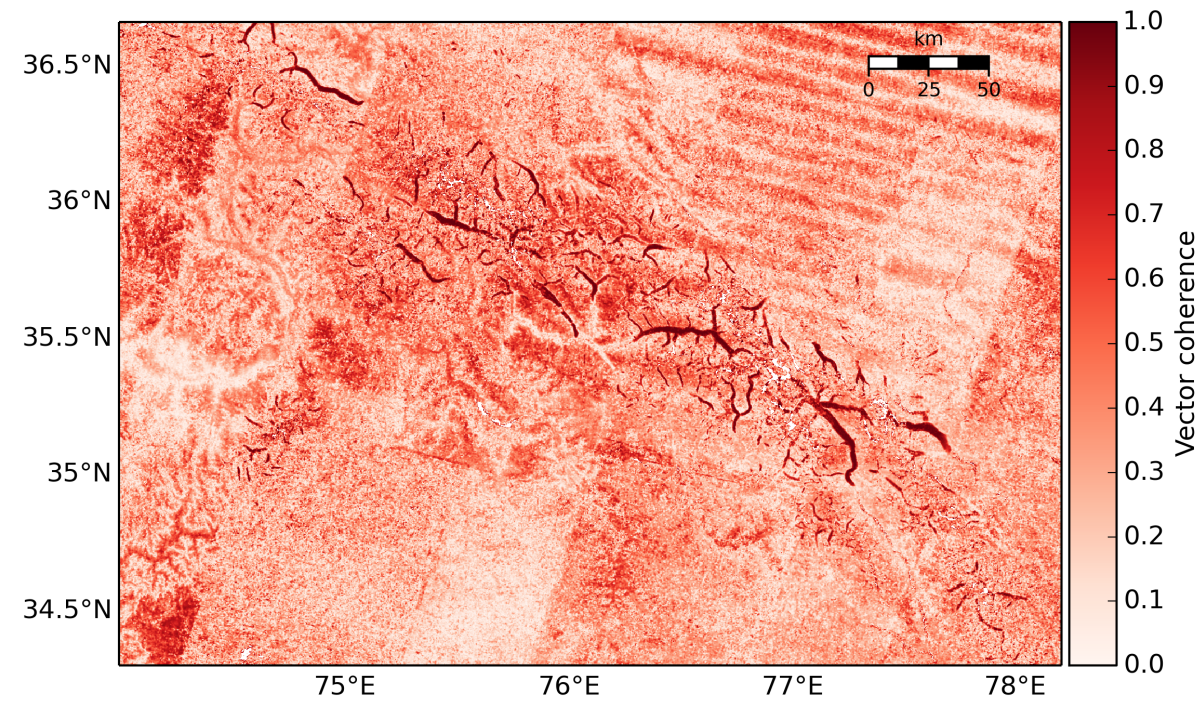

Figure 11: Velocity vector coherence for the Karakoram region. A value of 1 means perfect alignment of all the vectors contributing to the median velocity, 0 means completely random directions.

\section{Conclusions}

In this paper, we present a processing strategy to estimate mountain glacier velocities from a complete satellite archive. We select all possible pairs for a specific time span, avoiding the lengthy task of manually selecting the best available images. The pairs are then submitted to the same preprocessing steps and a feature-tracking algorithm is performed to produce surface velocity fields. Successful measurements are selected solely based on the quality of the correlation, and merged together. First, the most aberrant displacement values are rejected based on the confidence function returned by the feature-tracking algorithm; all points below a certain threshold are removed. Secondly, the results are filtered based on the spatial and temporal consistency of the displacement. A median filter is applied to the resulting stack of velocities on a pixel by pixel basis within 
a spatio-temporal neighborhood to obtain the final glacier velocity field.

This strategy has been applied to produce glacier annual velocity fields from a data set of 1536 pairs of Landsat 5 and 7 images acquired within a 3 year period and covering the Pamir-Karakoram-Himalaya region extending over $3000 \mathrm{~km}$. Results on a single Landsat frame shows that the percentage of successful measurements increases from $71 \%$ of glacierized area for the best available pair, to $94 \%$ for the merged results. In overall, it allows us to obtain a velocity estimate for $76000 \mathrm{~km}^{2}$ or $92 \%$ of the glacierized areas of this region. We then estimate the impact of the coregistration errors and variability of glacier flow on the final velocity over the Karakoram region (300x200km). The median $95 \%$ confidence interval is reduced to $2.0 \mathrm{~m} / \mathrm{yr}$ in stable areas and $4.4 \mathrm{~m} / \mathrm{yr}$ over glaciers thanks to the redundancy in the measurements.

The strategy has been applied to Landsat images but is flexible and could easily be applied to various sensors with different pixel resolution or wavelength, including radar. This would be particularly valuable for the upcoming Sentinel 1-2 missions of the European Space Agency that will provide repeated images of the Earth surface. This strategy can also be applied to derive not only annual but seasonal velocities using set of pairs with shorter time span. More complex postprocessing strategy as for example time series inversion (Lanari et al., 2007) to select the coherent displacements along the time serie could be implemented, potentially allowing to derive the seasonal velocity variations.

The analysis of complete satellite archives open new perspectives for the study of glacier's dynamic against physical parameters such as length, slope and debris cover, for the study of glacier response to climate changes, glacial geomorphology, erosion (Scherler et al., 2011a), glacial hazards (Bolch et al. 2008) and the estimation of the contribution of surface mass balance and ice fluxes to the observed glacier thinning/thickening (Berthier and Vincent, 2012).

Aknowledgements : Glacier outlines are downloaded from the GLIMS database http://glims.org/RGI/ except for outlines in the Baltoro area courtesy of Julie Gardelle. We would like to thank the USGS for making the Landsat 
archive freely available at http://earthexplorer.usgs.gov/. We are grateful to Urs Wegmüller and Charles Werner for their precious help in improving the feature-tracking code. Comments and suggestion of three anonymous reviewers greatly improved the quality of the paper. All processing with the exception of the feature-tracking have been performed using Python and GDAL. We thank the Tera_SAR (Mastodons CNRS) project for their support. This work is funded by the French National Center for Earth Observation (CNES), the Assembleee des Pays de Savoie (APS) and the GdR ISIS and supported by the Dragon 3 program, a partnership between the European Space Agency (ESA) and the National Remote Sensing Center of China (NRSCC).

\section{References}

Ahn, Y., Howat, I.M., 2011. Efficient automated glacier surface velocity measurement from repeat images using multi-image/multichip and null exclusion feature tracking. Geoscience and Remote Sensing, IEEE Transactions on 49, 2838-2846. URL: http://ieeexplore.ieee.org/xpls/abs_all.jsp? arnumber $=5738677$.

Barros, V., Field, C., Dokken, D., Mastrandea, M., Mach, K., Bilir, T., Chatterjee, M., Ebi, K., Estrada, Y., Genova, R., Girma, B., Kissel, E., Levy, A., MacCracken, S., Mastrandea, P., White, L., 2014. IPCC 2014 : Climate Change 2014: Impacts, Adaptation, and Vulnerability. Part B: Regional Aspects. Contribution of Working Group II to the Fifth Assessment Report of the Intergovernmental Panel on Climate Change. Cambridge university press, cambridge, united kingdom and new york, NY, USA ed.

Berthier, E., Raup, B., Scambos, T., 2003. New velocity map and mass-balance estimate of mertz glacier, east antarctica, derived from landsat sequential imagery. Journal of Glaciology 49, 503-511. doi $10.3189 / 172756503781830377$

Berthier, E., Vadon, H., Baratoux, D., Arnaud, Y., Vincent, C., Feigl, K.L., Remy, F., Legresy, B., 2005. Surface motion of mountain glaciers 
derived from satellite optical imagery. Remote Sensing of Environment

95, 14-28. URL: http://www.sciencedirect.com/science/article/pii/ S0034425704003463.

Berthier, E., Vincent, C., 2012. Relative contribution of surface mass-balance and ice-flux changes to the accelerated thinning of mer de glace, french alps, over 19792008. Journal of Glaciology 58, 501-512. doi 10.3189/ 2012JoG11J083.

Bhambri, R., Bolch, T., Kawishwar, P., Dobhal, D.P., Srivastava, D., Pratap, B., 2013. Heterogeneity in glacier response in the upper shyok valley, northeast karakoram. The Cryosphere 7, 1385-1398. URL: http://www. the-cryosphere.net/7/1385/2013/, doi 10.5194/tc-7-1385-2013.

Bolch, T., Buchroithner, M.F., Peters, J., Baessler, M., Bajracharya, S., 2008. Identification of glacier motion and potentially dangerous glacial lakes in the mt. everest region/nepal using spaceborne imagery. Nat. Hazards Earth Syst.

(1) Sci. 8, 1329-1340. URL: http://www.nat-hazards-earth-syst-sci.net/ 8/1329/2008/, doi:10.5194/nhess-8-1329-2008

Burgess, E.W., Forster, R.R., Larsen, C.F., 2013. Flow velocities of alaskan glaciers. Nature communications 4. URL: http: //www.nature.com/ncomms/2013/130716/ncomms3146/full/ncomms3146. html?message-global=remove\&WT .ec_id=NCOMMS-20130717.

Chu, J.T., 1955. On the distribution of the sample median. The Annals of 1. Mathematical Statistics 26, 112-116. URL:/http://www.jstor.org/stable/ 2236761 .

Copland, L., Pope, S., Bishop, M.P., Shroder, J.F., Clendon, P., Bush, A., Kamp, U., Seong, Y.B., Owen, L.A., 2009. Glacier velocities across the central karakoram. Annals of Glaciology 50, 4149. URL: http://www.ingentaconnect.com/content/igsoc/agl/2009/ $00000050 / 00000052 /$ art00006. 
Debella-Gilo, M., Kääb, A., 2012. Locally adaptive template sizes for matching repeat images of earth surface mass movements. ISPRS Journal of Photogrammetry and Remote Sensing 69, 10-28. URL: http://www.sciencedirect. com/science/article/pii/S092427161200038X.

Fallourd, R., Harant, O., Trouv, E., Nicolas, J.M., Gay, M., Walpersdorf, A., Mugnier, J.L., Serafini, J., Rosu, D., Bombrun, L., Vasile, G., Cotte, N., Vernier, F., Tupin, F., Moreau, L., Bolon, P., 2011. Monitoring temperate glacier displacement by multi-temporal TerraSAR-x images and continuous GPS measurements. IEEE Journal of Selected Topics in Applied Earth Observations and Remote Sensing 4, 372-386. doi:10.1109/JSTARS.2010.2096200

Fitch, A.J., Kadyrov, A., Christmas, W.J., Kittler, J., 2002. Orientation correlation., in: Proceedings of the British Machine Conference, BMVA Press. pp. 11.1-11.10. URL:http://citeseerx.ist.psu.edu/viewdoc/download? doi=10.1.1.19.7698\&rep=rep1\&type=pdf, doi:10.5244/C.16.11.

Gardner, A.S., Moholdt, G., Cogley, J.G., Wouters, B., Arendt, A.A., Wahr, J., Berthier, E., Hock, R., Pfeffer, W.T., Kaser, G., Ligtenberg, S.R.M., Bolch, T., Sharp, M.J., Hagen, J.O., van den Broeke, M.R., Paul, F., 2013. A reconciled estimate of glacier contributions to sea level rise: 2003 to 2009. Sci-

ence 340, 852-857. URL: http://www.sciencemag.org/cgi/doi/10.1126/ science.1234532, doi $10.1126 /$ science.1234532.

Goldstein, R.M., Engelhardt, H., Kamb, B., Frolich, R.M., 1993. Satellite radar interferometry for monitoring ice sheet motion: Application to an antarctic ice stream. Science 262, 1525-1530. URL: http://www.sciencemag.org/ content/262/5139/1525.short

Gourmelen, N., Kim, S.W., Shepherd, A., Park, J.W., Sundal, A.V., Björnsson, H., Palsson, F., 2011. Ice velocity determined using conventional and multiple-aperture InSAR. Earth and Planetary Science Letters 307, 156-160. URL: http://www.sciencedirect.com/science/article/ pii/S0012821X11002421 
Heid, T., Kääb, A., 2012a. Evaluation of existing image matching methods for deriving glacier surface displacements globally from optical satellite imagery. Remote Sensing of Environment 118, 339-355. URL: http: //www.sciencedirect.com/science/article/pii/S0034425711004214.

Heid, T., Kääb, A., 2012b. Repeat optical satellite images reveal widespread and long term decrease in land-terminating glacier speeds. The Cryosphere 6, 467-478. URL: http://www . the-cryosphere.net/6/467/2012/, doi 10 . 5194/tc-6-467-2012.

Immerzeel, W.W., Beek, L.P.H.v., Bierkens, M.F.P., 2010. Climate change will affect the asian water towers. Science 328, 1382-1385. URL: http://www. sciencemag.org/content/328/5984/1382, doi:10.1126/science.1183188

IPCC, 2013. Group I Contribution to the IPCC Fifth Assessment Report (AR5), Climate Change 2013: The Physical Science Basis. Intergovernmental Panel on Climate Change, Geneva, Switzerland.

Kääb, A., 2002. Monitoring high-mountain terrain deformation from repeated air-and spaceborne optical data: examples using digital aerial imagery and ASTER data. ISPRS Journal of Photogrammetry and remote sensing 57, 39-52. URL: http://www.sciencedirect.com/science/article/pii/ S0924271602001144.

Kääb, A., 2005. Combination of SRTM3 and repeat ASTER data for deriving alpine glacier flow velocities in the bhutan himalaya. Remote Sensing of Environment 94, 463-474. URL: http://linkinghub.elsevier.com/retrieve/ pii/S0034425704003475, doi:10.1016/j.rse.2004.11.003

Lanari, R., Casu, F., Manzo, M., Zeni, G., Berardino, P., Manunta, M., Pepe, A., 2007. An overview of the small baseline subset algorithm: A DInSAR technique for surface deformation analysis. Pure and Applied Geophysics 164, 637-661. URL: http://link.springer.com/article/10. 1007/s00024-007-0192-9. 
Lee, D., Storey, J., Choate, M., Hayes, R., 2004. Four years of landsat-7 on-orbit geometric calibration and performance. IEEE Transactions on Geoscience and Remote Sensing 42, 2786-2795. doi 10.1109/TGRS.2004.836769.

Luckman, A., Quincey, D., Bevan, S., 2007. The potential of satellite radar interferometry and feature tracking for monitoring flow rates of himalayan glaciers. Remote Sensing of Environment 111, 172-181. URL: http://www. sciencedirect.com/science/article/pii/S0034425707002842

Necsoiu, M., Leprince, S., Hooper, D.M., Dinwiddie, C.L., McGinnis, R.N., Walter, G.R., 2009. Monitoring migration rates of an active subarctic dune field using optical imagery. Remote Sensing of Environment 113, 2441-2447. URL: http://www.sciencedirect.com/science/article/pii/ S0034425709002168.

Paul, F., Bolch, T., Kääb, A., Nagler, T., Nuth, C., Scharrer, K., Shepherd, A., Strozzi, T., Ticconi, F., Bhambri, R., Berthier, E., Bevan, S., Gourmelen, N., Heid, T., Jeong, S., Kunz, M., Lauknes, T.R., Luckman, A., Merryman Boncori, J.P., Moholdt, G., Muir, A., Neelmeijer, J., Rankl, M., VanLooy, J., Van Niel, T., 2013. The glaciers climate change initiative: Methods for creating glacier area, elevation change and velocity products. Remote Sensing of Environment URL: http://www.sciencedirect.com/science/article/ pii/S0034425713003532, doi 10.1016/j.rse.2013.07.043

Pfeffer, W.T., Arendt, A.A., Bliss, A., Bolch, T., Cogley, J.G., Gardner, A.S., Hagen, J.O., Hock, R., Kaser, G., Kienholz, C., others, 2014. The randolph glacier inventory: a globally complete inventory of glaciers. Journal of Glaciology 60, 537. URL: http://www.igsoc.org/journal/60/221/j13J176.pdf.

Quincey, D.J., Braun, M., Glasser, N.F., Bishop, M.P., Hewitt, K., Luckman, A., 2011. Karakoram glacier surge dynamics. Geophysical Research Letters 38, L18504. URL: http://www.agu.org/pubs/crossref/ 2011/2011GL049004.shtml. 
Quincey, D.J., Copland, L., Mayer, C., Bishop, M., Luckman, A., Belo, M., 2009a. Ice velocity and climate variations for baltoro glacier, pakistan. Journal of Glaciology 55, 1061-1071. URL: http://www.ingentaconnect.com/ content/igsoc/jog/2009/00000055/00000194/art00011

Quincey, D.J., Luckman, A., Benn, D., 2009b. Quantification of everest region glacier velocities between 1992 and 2002, using satellite radar interferometry and feature tracking. Journal of Glaciology 55, 596606. URL: http://www.ingentaconnect.com/content/igsoc/jog/2009/ $00000055 / 00000192 /$ art00002.

Rankl, M., Kienholz, C., Braun, M., 2014. Glacier changes in the karakoram region mapped by multimission satellite imagery. The Cryosphere 8, 977989. URL: http://www.the-cryosphere.net/8/977/2014/, doi 10.5194/ tc-8-977-2014.

Redpath, T.A.N., Sirguey, P., Fitzsimons, S.J., Kääb, A., 2013. Accuracy assessment for mapping glacier flow velocity and detecting flow dynamics from ASTER satellite imagery: Tasman glacier, new zealand. Remote Sensing of a Environment 133, 90-101. URL:http://www.sciencedirect.com/science/ article/pii/S0034425713000485.

Rousseeuw, P.J., Hubert, M., 2011. Robust statistics for outlier detection. Wiley Interdisciplinary Reviews: Data Mining and Knowledge Discovery 1, 73-79. URL: http://onlinelibrary.wiley.com/doi/10.1002/widm.2/abstract doi:10.1002/widm.2.

Scambos, T.A., Dutkiewicz, M.J., Wilson, J.C., Bindschadler, R.A., 1992. Application of image cross-correlation to the measurement of glacier velocity using satellite image data. Remote Sensing of Environment 42,

177-186. URL: http://www.sciencedirect.com/science/article/pii/ 0034425792901010 .

Scherler, D., Bookhagen, B., Strecker, M.R., 2011a. Hillslopeglacier coupling: The interplay of topography and glacial dynam- 
ics in high asia. Journal of Geophysical Research: Earth Surface

116, F02019. URL: http://onlinelibrary.wiley.com/doi/10.1029/ 2010JF001751/abstract, doi:10.1029/2010JF001751

Scherler, D., Bookhagen, B., Strecker, M.R., 2011b. Spatially variable response of himalayan glaciers to climate change affected by debris cover. Nature Geo-

science 4, 156-159. URL: http://www.nature.com/doifinder/10.1038/ ngeo1068, doi $10.1038 /$ ngeo1068

Scherler, D., Leprince, S., Strecker, M.R., 2008. Glacier-surface velocities in alpine terrain from optical satellite imageryaccuracy improvement and quality assessment. Remote Sensing of Environment 112, 3806-3819. URL: http: //linkinghub.elsevier.com/retrieve/pii/S0034425708001934, doi 10 . $1016 /$ j.rse.2008.05.018.

Storey, J., Choate, M., 2004. Landsat-5 bumper-mode geometric correction. IEEE Transactions on Geoscience and Remote Sensing 42, 2695-2703. doi 10. 1109/TGRS.2004.836390

Strozzi, T., Luckman, A., Murray, T., Wegmuller, U., Werner, C.L., 2002. Glacier motion estimation using SAR offset-tracking procedures. Geoscience and Remote Sensing, IEEE Transactions on 40, 2384-2391. URL: http: //ieeexplore.ieee.org/xpls/abs_all.jsp?arnumber=1166597.

Tucker, C.J., Grant, D.M., Dykstra, J.D., 2004. NASA's global orthorectified landsat data set. Photogrammetric engineering and remote sensing 70, 313322. URL: http://lpais.fii.gob.ve/files/orto_lansat_nasa.pdf.

Willis, M.J., Melkonian, A.K., Pritchard, M.E., Ramage, J.M., 2012. Ice loss rates at the northern patagonian icefield derived using a decade of satellite remote sensing. Remote Sensing of Environment 117, 184-198. URL: http: //www.sciencedirect.com/science/article/pii/S0034425711003440. 